\title{
Obstetricians Presenting Amniocentesis to Pregnant Women: Practice Observed (*)
}

\author{
THERESA M. MARTEAU (**) \\ MARIANA PLENICAR (**) \\ JANE KIDD (**)
}

\section{INTRODUCTION}

There is widespread acknowledgment of the importance of non-directive counselling in achieving informed acceptance and informed decline of prenatal testing for fetal abnormalities (Royal College of Physicians, 1989). We do not, however, know the extent to which this is achieved. Few studies have documented what, and how, information is provided to women eligible for such tests.

The way in which information is presented may influence subsequent decision (McNeil et $a l, 1982)$. In an analogous study of prenatal testing, subjects were more likely to choose to have amniocentesis if the likelihood of having an affected child was framed negatively (i.e a $20 \%$ likelihood of having an affected child) than if the likelihood was framed positively (i.e an $80 \%$ li-

$\left(^{*}\right)$ We are grateful to the staff who so generously allowed us to study their consultations. Financial support for this project was provided by Womanschoice.

This paper was published as an original article in Journal of Reproductive and Infant Psychology, 1993, 11, 3-10.

Theresa M. Marteau is supported by the Wellcome Trust.

(**) Psychology \& Genetics Research Group, UMDs, Guy's Campus, London SE1 9RT, United Kingdom. kelihood that there is no abnormality; Marteau, 1989a). In a retrospective study of women referred for amniocentesis following an abnormal result on a routine screening test, maternal serum alpha-fetoprotein, women reported that they had been encouraged to undergo the test by their obstetricians (Farrant, 1985). Furthermore, Farrant argued that they were not provided with sufficient information with which to make an informed choice about whether to undergo amniocentesis. For example, of 112 women interviewed after amniocentesis, $24 \%$ were unaware that the procedure carried a risk of miscarriage. In another retrospective study of women's decisions regarding routine amniocentesis because of maternal age, the majority stated that their decisions were uninfluenced by the doctors and genetic counsellors they had seen as part of their routine care (Dixson et al., 1981).

It is difficult, however, to infer how amniocentesis was actually presented and the relative contribution that test presentation might have had upon test uptake in these studies, given that they used retrospective designs and relied exclusively upon self-reports of the women concerned. Thus far there have been no observational studies of how amniocentesis is presented by doctors to eligible women. The aim of the current study is therefore to describe how obstetricians present amniocentesis to women eligible 
because of their age and hence increased likelihood of having a child with Down's syndrome.

\section{METHODS}

\subsection{Sample}

The sample comprised routine consultations between 25 women and 17 doctors. They all took place over a 3-month period in 1989 in one London teaching hospital. The women were aged 36 years or over at the expected date of delivery (mean age $=39.5$, range $36-47$ ), and were less than 16 weeks pregnant at the time of their first consultations with a doctor in the antenatal clinic. They had all seen a midwife for a booking-in consultation. Amniocentesis is sometimes discussed during these consultations, but formal presentation of this test at the study hospital was seen as the province of obstetricians. None had undergone amniocentesis in a previous pregnancy. Over a period of 3 months, women eligible for amniocentesis solely because of maternal age, attending routine clinics, were invited to participate in the study. None refused. The doctors in the study ranged in grade from senior house officer to consultant.

\subsection{Measures}

The information provided during the consultation was coded under one of three categories: the conditions for which screening was being offered, including their nature, and likelihood of occurrence; the procedure of amniocentesis, including the likelihood of miscarriage; and the likely action following a positive result, including discussion of termination. Obstetricians' expressed attitudes towards the use of amniocentesis were also coded.

\subsection{Procedure}

Following agreement to participate from both doctors and women, a tape-recorder was placed in the consulting room, switched on by a researcher, who then left the room. After the consultation, the recorder was switched off. Tapes were transcribed and information about amnio- centesis was coded, using a coding frame based on the categories shown in Table 1.

\section{RESULTS}

Of the 25 women tape-recorded,23 subsequently underwent amniocentesis. The test was discussed in all 25 consultations. The information provided most frequently concerned the probability of having a child with Down's syndrome ( 21 occasions) and the probability of the procedure resulting in miscarriage (21 occasions). The probability of each of these events was contrasted on 14 occasions. Termination was mentioned in a minority of consultations (Table 1).

The test was first mentioned in the consultation by the doctor on 18 occasions, and by the woman on seven. The primary condition for which screening was being offered, Down's syndrome, was mentioned in 22 consultations, but never described. On eight occasions it was mentioned that other chromosome anomalies aside from Down's syndrome were looked for. On five occasions, doctors mentioned that amniocentesis did not screen for all possible abnormalities. None of these conditions were ever described, e.g (107):

Dr: ... it doesn't necessarily guarantee you a normal baby but it does exclude some of the more common abnormalities which are associated with us ladies as we get a bit older and we have our babies.

On four occasions, women were led to believe that the test was more general than it actually is, e.g. (104):

W: And that can actually tell exactly how the baby is?

Dr: Yes, it tells by its chromosomes so it tells you if its a perfectly normal boy or girl. They don't tell you whether its a boy or a girl, they just tell you it's a normal baby and then keep the sex a surprise.

\subsection{Probability of Down's syndrome}

The probability of Down's syndrome was re- 
TABLE 1

Information presented about amniocentesis during 25 routine consultations

\section{Condition test screens for}

Down's syndrome $\quad 22$

Other chromosome anomalies $\quad 8$

$\begin{array}{ll}\text { Spina bifida } & 6\end{array}$

Description of conditioms

Down's syndrome $\quad 0$

Other chromosome anomalies $\quad 0$

$\begin{array}{ll}\text { Spina bifida } & 0\end{array}$

Presentation of likelihood

Down's syndrome: $\quad 21$

Numbers $\quad 9$

Verbal description of likelihood $\quad 6$

Numerical and verbal descriptor $\quad 6$

Other chromosome anomalies $\quad 0$

$\begin{array}{ll}\text { Spina bifida } & 0\end{array}$

2. Amniocentesis

$\begin{array}{ll}\text { Likelihood of miscarriage } & 21\end{array}$

Numbers $\quad 8$

Verbal descriptors of likelihood 3

$\begin{array}{ll}\text { Numbers and verbal description } & 10\end{array}$

Comparison of likelihood of Down's syndrome with those of fetal loss following amnio-

centesis 14

3. Meaning of results

Implications of negative result does not mean baby is free of all congenital problems 3

Implications of positive result

$\begin{array}{ll}\text { Possible action, including termination } & 9\end{array}$

4. Obstetricians' attitudes towards amniocentesis

Attitude made explicit 15

$\begin{array}{ll}\text { Expressed before woman's choice evident } & 10\end{array}$

Expressed after woman's choice evident 5

presented numerically on nine occasions, e.g. (102):

Dr: The risk of you getting a Down's baby is 1 in 157

e.g (103)

Dr: ... now by the time you are 40 the risk is 1 in $100 \ldots$ when you are 41 the risk has gone up to 1 in $88 \ldots$

On six occasions the risk was presented nonnumerically, e.g (024):

Dr: ... your risk starts to increase after the age of 37 years. Each year it gets higher. So I think if you're 40 now its a reasonable thing to do.

e.g (008):

Dr: Your chances for a baby with Down's syndrome goes up as the years go by.

On six occasions the probability was presented numerically and then qualified verbally. e.g. (104)

Dr: Right, then the risk of you having a Down's baby is 1 in 120 , approximately. 119 
times out of 120 you'll have a normal baby, so it's quite high really.

e.g (109):

Dr: Your risk of having a Down's baby at 39 is approximately 1 in $160 \ldots$ is a possibility, a 1 in 160 possibility... and it's too high for you to take.

\subsection{Probability of miscarriage following am- niocentesis}

The probability of miscarriage following amniocentesis was presented in 21 consultations. On the majority of occasions these were presented using numbers, sometimes in conjunction with qualifying adjectives. Most often the likelihood of a miscarriage was presented in conjunction with the likelihood of having a baby with Down's syndrome (14/21), e.g (019):

Dr: And the risk of a miscarriage is probably about 1 in 150. So the risk of a miscarriage is less than the risk of having a Down's. So you're more likely to have a Down's than have a miscarriage after amniocentesis.

e.g. (048):

Dr: ...Yes, I think that really the risks of it (Down's syndrome) outweigh the risks of amniocentesis.

\subsection{Perceptions of risk}

The qualitative descriptions attached to numerical probabilities varied across doctors and with the nature of the event being described. For example, while one doctor described the probability of 1 in 120 for a child with Down's syndrome as quite high (104), another described the probability of 1 in 80 or 90 as being in the woman's favour (105).

All doctors referred to probabilities as risks. The probability of miscarriage tended to be described as low, while similar probabilities of having an abnormal baby tended to be described as high. A miscarriage rate of 1 in 100 was variously described as small $(071 ; 008 ; 046)$ very small (046), and very rare (017). By contras:, risks of 1 in 120 and 1 in $160(104 ; 109)$ for a baby with Down's syndrome were described as high.

\subsection{Misinformation}

The probabilities given for both amniocentesis and Down's syndrome varied, and hence, were sometimes inaccurate. For example, the probabilities presented for a miscarriage following amniocentesis varied from «higher than 1 in 100 » $(107)$ to «1 in 300 or $400(008) »$ (true estimate $=$ 1:100; Tabor et al., 1986). The probabilities presented for a baby having Down's syndrome varied. One 40 year old woman was told that it was 1 in 157 (102), another 40 year old that it was 1 in 180 (103), yet another that it was as high as 1 in 50 (101) (true estimate 1:112, Harper, 1991)

\subsection{Termination}

Termination of pregnancy following diagnosis of a fetal abnormality was mentioned on nine occasions. Sometimes it was mentioned by the obstetrician when making explicit the terms under which amniocentesis would be conducted, e.g. (055):

Dr: I mean, obviously if you have the test done, the understanding is on your side as well that you will act on the results if they are found to be abnormal.

e.g.(024)

Dr: Do you understand that if you don't want a termination there is no reason going through with it?

Not all obstetricians held this view about the need for a woman to state her decision regarding termination if the result showed an abnormality prior to amniocentesis, e.g. (103):

Dr: ...There is not much point in having the test (amniocentesis) if you don't (want a termination), although people don't know how they are going to react if they are told that sort of thing (that the baby has an abnormality).

Women's attitudes towards termination for a fetal abnormality were never elicited directly, although they were sometimes given by women: e.g (101) 
W: I don't want it (amniocentesis). The thing is, if anything is wrong, I could never justify an abortion.

\subsection{Attitudes towards abnormality}

These were discussed, elicited or mentioned by doctors on just one occasion, when a woman who declined amniocentesis stated that the birth of a child with Down's syndrome would not be the end of the world (see 002 below)

\subsection{Obstetrician's attitudes towards amnio- centesis}

In 15 of the consultations the attitudes of the obstetrician towards the use of amniocentesis for women at risk of having a baby with Down's syndrome because of raised age, was evident.

On ten occasions the attitude was expressed before the woman's choice was evident; on five occasions it was expressed after she had stated a choice. On nine occasions when attitudes were expressed to women who had made their choices explicit, the obstetricians' attitudes were positive towards the use of amniocentesis, e.g. (061), to a woman aged 47:

Dr: ... and certainly obviously at your age we would strongly advise the amniocentesis test whereby we can test the chromosome development in the baby and exclude Down's syndrome.

Dr: If you were my wife I would advise amniocentesis.

A less positive, more neutral attitude towards amniocentesis was evident on just one occasion, for a woman pregnant with twins through IVF, (105):

Dr: ... at 41 obviously the risk of having such a problem (Down's syndrome) is probably about 1 in 80 or $90 \ldots$ I mean the odds are very much in your favour...

On three of the five occasions when attitudes were expressed after women had expressed a choice, these attitudes echoed women's choices, which were to undergo the procedure, e.g. (046):

Dr: ... I would do the same thing in your position

e.g (008):
Dr: ... I think you're very wise.

On the other two occasions when obstetricians expressed their attitudes towards the use of amniocentesis after the woman had made her choice, these attitudes were contrary to the decision that both women made, not to undergo amniocentesis. In both cases, the obstetricians attempted to dissuade women from this decision. Seemingly, in an attempt to dissuade a 40 year old woman from declining amniocentesis, the doctor presented the probability of Down's syndrome as twice as high as it actually was (101):

W: You can talk about it until you are blue in the face; but you won't change my mind

Dr: So, O.K you know the statistics... the chance of you having a baby with Down's syndrome could be as high as 1 in 50 .

The other woman who stated that she did not want amniocentesis was asked to consider giving birth to a baby with Down's syndrome, e.g. (002):

W: I just don't feel that there is any need (to have amniocentesis) and I don't want to take the risk and there is a small risk.

Dr: The risk of having a miscarriage after an amniocentesis is what, something between 1 in 150 to 200 pregnancies. But your risk of having a baby with Down's syndrome is higher than that risk of miscarriage. Now what would you feel if you had a baby with Down's syndrome?

W: Well, I'm a Nursery Nurse. I have worked with all types of children so therefore it wouldn't be the end of the world.

\section{DISCUSSION}

This small descriptive study illustrates a large degree of uniformity in the way that amniocentesis is routinely offered by obstetricians to women at increased risk of having a baby with Down's syndrome, because of maternal age. Presentations focused upon the risks of fetal abnormality and the risks of pregnancy loss following amniocentesis. The probabilities of the two events were contrasted on half the occasions when they were presented. Implicit in obstetricians' presentations was a positive attitude towards the use of amniocentesis in routine pre- 
gnancies in older women. An assumption that all women would or should undergo the procedure was also evident.

Three characteristics of test presentation deserve comment: first, the terms used to denote probability; second, the implicit assumption about an appropriate decision, and third, obstetricians' perceptions of the basis upon which decisions about whether to undergo amniocentesis are made.

The term risk was used to denote probability, and frequently it was used in conjunction with words to denote value. Such a blurring of probability and value goes against the stated objectives of genetic counselling (Coté, 1982), and the stated objectives of prenatal testing (Black Report, 1979: Royal College of Physicians, 1989). Coté argues for the importance of the terms chosen to denote probabilistic information if the purveyor of that information wishes to stay neutral. Words like probability, likelihood, chances, odds and recurrence rates do not invoke a notion of danger, burden or value as implied by the term risk. Risks are something to be avoided; probabilities are information to be considered in making a decision.

Although obstetricians frequently presented probabilistic information, there was a tendency for this to be presented in a binary fashion, that is, as denoting a high or low risk. This phenomenon has been documented in recipients of genetic counselling, for whom recurrence was perceived as either something that would or would not happen (Lippman-Hand \& Fraser, 1979). That health professionals too might use this heuristic in considering risk requires further study.

Emphasizing probabilistic information with inherent values (e.g. a risk of 1:100 for fetal loss is low; a risk of 1:100 for Down's syndrome is high) misrepresent how decisions about whether to undergo amniocentesis are made. At least two factors are relevant. First, it is a woman's perception of the likelihood of having an affected child that influences her decision, not the actual risk (Marteau et al, 1991). Second, concern about miscarriage also predicts uptake (Marteau et al 1989). Hence, not all women will view the probability of 1:100 for fetal loss as low, nor one of 1:100 for the likelihood of Down's syndrome as high.

We do not know how satisfied women were with this style of presentation. If most women had made their decisions about whether to undergo amniocentesis before their consultations, as suggested by Dixson and colleagues (Dixson et al 1981) they may have found the presentation a comforting confirmation of their decision. It may, however, be a less comforting style for those who had decided not to undergo the procedure. For women who enter the consultation undecided about whether to undergo amniocentesis, they may find the directive style eases the burden of decision-making, as suggested in a recent study of routine general practice consultations (Savage \& Armstrong, 1990). Given the potentially serious consequences of this decision, namely diagnosis and termination of an affected child, or loss of an unaffected fetus, decisions that do not reflect the views of a woman and her partner may adversely affect their ability to cope with these outcomes.

Little attention was paid to the nature of the conditions for which testing was being offered. No descriptions were provided for any of the conditions mentioned. Nor were women's understanding of the conditions determined. As part of the routine amniocentesis for maternal age, all 23 pairs of chromosomes are examined. Between the ages of 35 and 42, Trisomy 21 (Down's syndrome) only accounts for about $50 \%$ of chromosome anomalies detected at amniocentesis (Harper, 1991). That other chromosome anomalies will be checked was mentioned in just under a third of consultations. The frequency with which they occur was never mentioned. These results suggest that women are not routinely informed about the conditions for which their fetuses are being tested. This may in part explain the confusion and distress for patients and health professionals that occur following diagnosis of chromosomal anomalies, other than that of Down's syndrome (Rothman, 1986; Morrison \& Nevin, 1991). It has also been suggested that whether parents are told about the possibility of sex chromosome anomalies being detected by amniocentesis, prior to the procedure, influences their decisions about termination of such pregnancies (Robinson et al, 1989).

Rarely were women informed about the conditions for which amniocentesis would not test. On a few occasions, the study doctors stated that receipt of a normal result on this test meant that 
the baby would be normal. Routinely available prenatal tests however, test for fewer than $50 \%$ of serious birth abnormalities. Furthermore, no mention was ever made of the occasional need to repeat the test, following failure to culture any cells from the sample obtained. By omitting such information, doctors may be encouraging a false sense of reassurance for women undergoing these tests.

Occasionally, doctors presented women with misinformation. This appeared to reflect both a lack of knowledge, and attempts to persuade women. The variation in reporting of the miscarriage rate following amniocentesis perhaps reflected a lack of knowledge of the results from controlled trials. When this information was incorrect, it was always an underestimate of the rate, suggesting that physicians wish to minimize this risk, perhaps in an attempt to persuade women to undergo the procedure.

Possible factors influencing the presentation of amniocentesis include the amount of time available in consultations, the knowledge, attitudes and skills of obstetricians, as well as the attitudes of pregnant women.

A feeling of insufficient time to discuss tests in more detail during a routine consultation may have contributed to the omission of detailed information about amniocentesis. Doctors may also be presenting this test briefly because they lack the knowledge to talk about it at greater length. Evidence that staff lack optimal knowledge about screening is provided by a study of midwives in Sweden. Forty-five percent of 148 midwives were found to lack the basic knowledge about AFP (alpha-fetoprotein screening for increased risk of open neural tube defects) required to inform women about this test, which they were routinely presenting as part of antenatal care (Sanden, 1985).

Several attitudes may have influenced test presentation. The brevity of presentation, for example, may have arisen from doctors' attitudes to patients' needs for information. It is well documented that doctors underestimate patients' need for information and their ability to understand such information (Marteau, 1989b). It may also reflect doctors' fears that providing too much information will make patients anxious. There is little foundation for such a fear. The majority of studies report either an anxiety- reducing effect of information, or no effect of information upon anxiety (Ley, 1988). Only very occasionally has information been found to raise anxieties (e.g Visser, 1980). Other studies suggest that the impact of information will vary according to the individual's coping style (Miller and Mangan, 1983). Studies are needed to determine doctors' beliefs and attitudes about giving information to patients.

A brief presentation which does not emphasize patient choice may reflect doctors' views on the purpose of presenting prenatal screening. There is disagreement as to the purpose of presenting prenatal screening tests. While some hold with the view that the purpose is to reduce the incidence of birth abnormalities (Wald, 1991) others have argued that the purpose of presenting prenatal screening is to provide prospective parents with information about the tests to facilitate an informed decision about their use (Royal College of Physicians, 1989).

A further factor influencing how this test is presented may be doctors' skills at presenting information. Skills that were evident included support for the decisions that women made. The data would suggest, however, that this reflected support for a decision with which the doctor agreed. When positive attitudes were expressed, these occurred when women agreed to undergo amniocentesis. Negative attitudes were expressed when women declined the test. Expressing positive attitudes towards amniocentesis prior to a woman stating her choice demonstrates the directive nature of some consultations. Obstetricians do not receive training either in how to present information about prenatal tests or in communication skills more generally.

Alternatively, doctors may have the skills to present the test in an informative way for the patient to decide about uptake, but attempt to encourage test uptake. There are several reasons for this, including a belief that medical surveillance is an important part of obstetric care, that fetal abnormality is to be avoided at all costs, or that failure of women to undergo tests may result in litigation if subsequently a child with an abnormality is born. Such concerns will conflict with the need to provide patients with information to facilitate an informed decision about test uptake.

It is also possible that while staff presenta- 
tions may at some time have reflected their attitudes towards testing, their current presentations are now habitual, that is, they are relatively invariant with little need for close conscious attendance on the part of the performer (Oldfield, 1959). Such an explanation may reflect the reliance in the UK on a master-apprentice model of clinical practice.

In addition to the influence that staff bring to bear upon how prenatal screening tests are discussed in the consultation, the knowledge, attitudes and behaviour of women are likely to influence how these tests are presented. This was not assessed in the current study. The prospect of fetal abnormality may be too distressing or threatening for both women and obstetricians to discuss at length. While $62 \%$ of women reported after their babys' births that they had been concerned about a fetal abnormality during pregnancy, only $17 \%$ of them reported this fear while pregnant (Royal College of Midwives, 1966). Reluctance to acknowledge this fear overtly may therefore be one factor keeping discussion of prenatal screening for fetal abnormalities to a minimum.

It is now known whether tape-recording these consultations altered the behaviour of obstetricians or women. In a recent study in which over 2000 consultations in primary care were recorded, no evidence was found for associated changes in doctors' behaviour. (Redman et al, 1989).

The results are similar to those of another study of ours describing the presentation by obstetricians and midwives of routine AFP screening for spina bifida and Down's syndrome (Martea.u et al, 1992). Such results highlight the lack of training for obstetricians in presenting complex information about prenatal testing in ways compatible with informed consent. Training will need to address attitudes of doctors towards giving information and towards women's roles in deciding about prenatal testing, in addition to increasing their knowledge and skills in providing information. Before any training can be carried out, however, the most effective and efficient ways of achieving this need to be determined through controlled, empirically-based studies.

\section{REFERENCES}

Black Report (1979). Report of the Working Group on the Screening for Neural Tube Defects. London: Department of Health and Social Security.

Coté, G.B. (1982). Odds in genetic counselling. Journal of Medical Genetics, 19, 455-457.

Dixson, B., Richards, T.L., Reinsch, S., Edrick, V.B., Matson, M.R., \& Jones, O.W. (1981). Midtrimester amniocentesis: subjective maternal responses. Journal of Reproductive Medicine, 26, 10-16.

Farrant, W. (1985). "Who's for amniocentesis?» The politics of prenatal screening. In H. Homans (Ed.), The Sexual Politics of Reproduction (pp. 96-177). London: Gower.

Harper, P.S. (1991). Practical Genetic Counselling, 3rd edn. Oxford: Butterworth-Heinemann.

Ley, P. (1988). Communicating with Patients: Improving Communication, Satisfaction and Compliance. London: Croom-Helm.

Lippman-Hand, A., \& Fraser, F.C. (1979). Genetic counselling - the postcounselling period: 1 . Parents' perceptions of uncertainty. American Journal of Medical Genetics, 4, 51-71.

McNeil, B.J., Pauker, S.G., Sox, H.C., \& Tversky, A. (1982). On elicitation of preferences for alternative therapies. New England Journal of Medicine, 306, 1259-1262.

Marteau, T.M. (1989a). Framing of information: its influence upon decisions of doctors and patients. British Journal of Social Psychology, 28, 89-94.

Marteau, T.M. (1989b). The ethics of clinical research. British Medical Journal, 299, 513-514.

Marteau, T.M., Johnston, M., Shaw, R.W., \& Slack, J. (1989). Factors influencing the uptake of screening for open neural-tube defects and amniocentesis to test for Down's syndrome. British Journal of Obstetrics and Gynaecology, 96, 739-741.

Marteau, T.M., Kidd, J., Cook, R., Michie, S., Johnston M., Slack, J., \& Shaw, R.W. (1991). Perceived risk not actual risk predicts uptake of amniocentesis. British Journal of Obstetrics and Gynaecology, 98 , 282-286.

Marteau, T.M., Slack, J., Kidd, J., \& Shaw, R.W. (1992). Presenting a routine screening test in antenatal care: practice observed. Public Health, 106, 131-141.

Miller, S.M., \& Mangan, C.E. (1983). Interacting effects of information and coping style in adapting to gynaecological stress: should the doctor tell all? Journal of Personality and Social Psychology, 45, 223-236.

Morrison, P.J., \& Nevin, N.C. (1991). Non-directive genetic counselling. Lancet, 338,1267.

Oldfield, R.C. (1959). The analysis of human skill. In P. Halmos, \& A. Iliffe (Eds) Readings in General Psychology. Sevenoaks: Routledge \& Kegan Paul. 
Redman, S., Dickinson, J.A., Cockburn, J., Hennrikus, D., \& Sanson-Fisher, R.W. (1989). The assessment of reactivity in direct observation studies of doctorpatient interactions. Psychology and Health, 3, 17-28.

Robinson, A., Bender B.G., \& Linden, M.G. (1989). Decisions following the intrauterine diagnosis of sex chromosome aneuploidy. American Journal of Medical Genetics, 34, 552-554.

Rothman, B.K. (1986). The Tentative Pregnancy. Prenatal Diagnosis and the Future of Motherhood. New York: Viking.

Royal College of Midwives (1966). Preparation for Parenthood. London: Royal College of Midwives.

Royal College of Physicians (1989). Prenatal Diagnosis and Genetic Screening: Community and Service Implications. London: Royal College of Physicians.

Sanden, M-L. (1985). Midwives' knowledge of the alpha-fetoprotein test. Journal of Psychosomatic Obstetrics and Gynaecology, 4, 23-30.

Savage, R., \& Armstrong, D. (1990). Effects of a general practitioner's consulting style on patients' satisfaction: a controlled study. British Medical Journal, 301, 968-970.

Tabor, A., Madsen, M., Obel, E.B., Philip, J., Bang, J., \& Norgaard-Pedersen, B. (1986). Randomised controlled trials of genetic amniocentesis in 4606 low risk women. Lancet, $i, 1287-1292$.

Visser, A.Ph. (1980). Effects of an information booklet on well-being of hospital patients. Patient Counselling and Health Education, 2, 51-64.

Wald, N.J. (1991) Couple screening for cystic fibrosis. Lancet, 338: 1318-1319.

\section{ABSTRACT}

The aim of this study is to describe how obstetricians present amniocentesis to women eligible because of their age and hence increased likelihood of having a child with Down's syndrome and other chromosome abnormalities. Routine antenatal consultations between 25 women and 17 doctors were tape recorded. Presentations focused upon the risks of fetal abnormality, and the risks of pregnancy loss following amniocentesis. The word risk was used to denote probability and frequently used in conjunction with words to denote value. Although obstetricians frequently presented probabilistic information, this tended to be presented in a binary fashion, that is, as denoting either high or low risk. Equivalent probabilities were described as low in connection with fetal loss, and high in connection with Down's syndrome. The probabilities of these two events were contrasted on half of the occasions when they were presented. Implicit in obstetricians' presentations of amniocentesis was an assumption that all women would or should undergo the procedure. Information concerning the range of conditions detected at routine amniocentesis were infrequently mentioned and never described. The results of this descriptive study illustrate that information germane to decisions of whether to undergo amniocentesis is frequently presented in such a way as to encourage uptake of the test, rather than to foster informed decision-making.

\section{RESUMO}

O objectivo deste estudo é descrever como os obstetras apresentam a amniosíntese a mulheres que por causa da idade, têm uma probabilidade elevada de ter uma criança com síndrome de Down, ou com outra anormalidade cromossómica. Consultas de rotina prénatal foram gravadas entre 25 mulheres e 17 médicos. A apresentação do teste focou-se em relação aos riscos de anomalia fetal, e aos riscos de perda do feto a seguir à amniosíntese. A palavra «risco» foi usada para designar probabilidade e foi frequentemente usada em conjunto com palavras para designar valor. Ainda que os obstetras tenham apresentado frequentemente informação probabilística, esta foi apresentada de forma binária, isto é, designando alto ou baixo risco. Da mesma maneira, as probabilidades foram descritas como baixas em relação à perda do feto, e altas em relação ao sindrome de Down. As probabilidades destes dois eventos foram contrastadas em metade das ocasiões em que foram apresentadas. Na apresentação da amniosíntese feita pelos obstetras, estava implicita a suposição de que todas as mulheres deviam ser submetidas ao teste. Informação relativa ao leque de possíveis anomalias detectáveis pela amniosíntese, não foi mencionada frequentemente, e as anomalias nunca foram descritas. Os resultados deste estudo descritivo ilustram que a informação relevante para a tomada de decisão relativa à realização da amniosintese, é frequentemente apresentada de forma a favorecer a realização do teste, em vez de fornecer a informação necessária à tomada de decisão sobre a realização do mesmo. 